\title{
Air pollution, lung function and COPD: results from the population-based UK Biobank study
}

\author{
Dany Doiron ${ }^{1,2,3}$, Kees de Hoogh ${ }^{2,3}$, Nicole Probst-Hensch ${ }^{2,3}$, Isabel Fortier ${ }^{1}$, \\ Yutong $\mathrm{Cai}^{4,5}$, Sara De Matteis ${ }^{6}$ and Anna L. Hansell $\circledast^{4,7}$ \\ Affiliations: ${ }^{1}$ Research Institute of the McGill University Health Centre, Montreal, QC, Canada. ${ }^{2}$ Swiss Tropical \\ and Public Health Institute, Basel, Switzerland. ${ }^{3}$ University of Basel, Basel, Switzerland. ${ }^{4}$ Dept of \\ Epidemiology and Biostatistics, School of Public Health, Imperial College London, London, UK. ${ }^{5}$ Dept of \\ Analytical, Environmental and Forensic Sciences, School of Population Health and Environmental Sciences, \\ King's College London, London, UK. 'National Heart and Lung Institute, Imperial College London, London, \\ UK. ${ }^{7}$ Centre for Environmental Health and Sustainability, University of Leicester, Leicester, UK.
}

Correspondence: Dany Doiron, Research Institute of the McGill University Health Centre, 2155 rue Guy, office 458, Montreal, QC, Canada, H3H 2R9. E-mail: dany.doironamail.mcgill.ca

@ERSpublications

In one of the largest analyses to date, ambient air pollution exposure was associated with lower lung function and increased COPD prevalence, with stronger associations seen in those with lower incomes http://bit.ly/2DLBPA6

Cite this article as: Doiron $\mathrm{D}$, de Hoogh $\mathrm{K}$, Probst-Hensch $\mathrm{N}$, et al. Air pollution, lung function and COPD: results from the population-based UK Biobank study. Eur Respir J 2019; 54: 1802140 [https://doi. org/10.1183/13993003.02140-2018].

ABSTRACT Ambient air pollution increases the risk of respiratory mortality, but evidence for impacts on lung function and chronic obstructive pulmonary disease (COPD) is less well established. The aim was to evaluate whether ambient air pollution is associated with lung function and COPD, and explore potential vulnerability factors.

We used UK Biobank data on 303887 individuals aged 40-69 years, with complete covariate data and valid lung function measures. Cross-sectional analyses examined associations of land use regression-based estimates of particulate matter (particles with a 50\% cut-off aerodynamic diameter of 2.5 and $10 \mu \mathrm{m}$ : PM2.5 and PM10, respectively; and coarse particles with diameter between $2.5 \mu \mathrm{m}$ and $10 \mu \mathrm{m}$ : PMcoarse) and nitrogen dioxide $\left(\mathrm{NO}_{2}\right)$ concentrations with forced expiratory volume in $1 \mathrm{~s}$ (FEV1), forced vital capacity (FVC), the FEV1/FVC ratio and COPD (FEV1/FVC <lower limit of normal). Effect modification was investigated for sex, age, obesity, smoking status, household income, asthma status and occupations previously linked to COPD.

Higher exposures to each pollutant were significantly associated with lower lung function. A $5 \mu \mathrm{g} \cdot \mathrm{m}^{-3}$ increase in PM2.5 concentration was associated with lower FEV1 $(-83.13 \mathrm{~mL}, 95 \%$ CI $-92.50--73.75 \mathrm{~mL})$ and FVC $(-62.62 \mathrm{~mL}, 95 \% \mathrm{CI}-73.91--51.32 \mathrm{~mL})$. COPD prevalence was associated with higher concentrations of PM2.5 (OR 1.52, 95\% CI 1.42-1.62, per $5 \mu \mathrm{g} \cdot \mathrm{m}^{-3}$ ), PM10 (OR 1.08, 95\% CI 1.00-1.16, per $5 \mu \mathrm{g} \cdot \mathrm{m}^{-3}$ ) and $\mathrm{NO}_{2}$ (OR 1.12, 95\% CI 1.10-1.14, per $10 \mu \mathrm{g} \cdot \mathrm{m}^{-3}$ ), but not with PMcoarse. Stronger lung function associations were seen for males, individuals from lower income households, and "at-risk" occupations, and higher COPD associations were seen for obese, lower income, and non-asthmatic participants.

Ambient air pollution was associated with lower lung function and increased COPD prevalence in this large study.

This article has supplementary material available from erj.ersjournals.com

Received: Nov 082018 | Accepted after revision: April 222019

Copyright OERS 2019 


\section{Introduction}

Ambient air pollution increases the risk of respiratory mortality, but evidence for impacts on lung function and obstructive lung disease is less well established. Recent studies and reviews have reported suggestive evidence linking outdoor air pollution and lung function and chronic obstructive pulmonary disease (COPD) [1-4]. Recently, the European Study of Cohorts for Air Pollution Effects (ESCAPE) project showed that higher ambient nitrogen dioxide $\left(\mathrm{NO}_{2}\right)$ and exposure to particulate matter with a $50 \%$ cut-off aerodynamic diameter of $10 \mu \mathrm{m}$ (PM10), as well as higher traffic load on roads near residences were associated with impaired lung function in adults, using a meta-analysis across five European cohorts [5]. A separate meta-analysis of four of these same cohorts found positive but nonsignificant associations between chronic exposure to ambient air pollution and COPD [6]. Other large studies have not shown consistent evidence of long-term air pollution exposure on adult-onset COPD $[7,8]$. Inconclusive findings have been, in part, attributable to lack of statistical power to detect small effects. Sample size limitations have also curtailed exploration of associations among population subgroups.

The objectives of this cross-sectional study were to examine whether air pollution was associated with lung function and COPD using a very large UK study. Secondly, potential vulnerability factors of the relationships between air pollution and lung function and COPD were explored.

\section{Methods}

\section{Study participants}

We used baseline questionnaire, anthropometric measures and spirometry data from the UK Biobank collected in 2006-2010. UK Biobank is a national cohort study of half a million participants aged 4069 years, largely in urban areas of England, Wales and Scotland recruited from the UK National Health Services register [9]. Full study sampling methods are described elsewhere [9, 10]. A research protocol for our study obtained all necessary approvals from the UK Biobank's review committees.

\section{Lung function and COPD}

Trained healthcare technicians and nurses in UK Biobank assessment centres performed pre-bronchodilation lung function tests using the Vitalograph Pneumotrac 6800 spirometer (Maids Moreton, UK). Contraindications were chest infection in the past month; history of detached retina, heart attack or surgery to eyes, chest or abdomen in past 3 months; history of a collapsed lung; pregnancy (1st or 3rd trimester); or currently on medication for tuberculosis. Two blows were recorded for each participant and a third blow was administered if the differences between both forced vital capacity (FVC) and forced expiratory volume in $1 \mathrm{~s}(\mathrm{FEV} 1)$ of the first two blows were $>5 \%$. Acceptability of spirometry data was assessed by quality appraisal of a sample of manoeuvres, as described previously [11]. The highest values for both FVC and FEV1 from acceptable blows were used in analyses. Participants reporting having smoked or used an inhaler within an hour prior to spirometry testing were excluded.

To adjust for normative ageing effects as well as variations according to sex, height and ethnicity, we defined COPD outcomes using the Global Lung Function Initiative (GLI) 2012 reference values for lower limit of normal (LLN) [12], which were computed using the GLI R macro [13]. Individuals with a FEV1/ FVC ratio below the LLN were classified as having COPD [14].

\section{Air pollution estimates}

Land use regression (LUR)-based estimates of $\mathrm{NO}_{2}, \mathrm{PM} 10$, fine particles with diameter $<2.5 \mu \mathrm{m}(\mathrm{PM} 2.5)$, and coarse particles with diameter between $2.5 \mu \mathrm{m}$ and $10 \mu \mathrm{m}$ (PMcoarse) for 2010 were generated as part of ESCAPE $[15,16]$ and linked to geocoded residential addresses of UK Biobank participants. Predictor variables used in final pollutant-specific LUR models and model $\mathrm{R}^{2} \mathrm{~s}$ are presented in supplementary table S1. Leave-one-out cross-validation, where each site is left out sequentially while the included variables of the models are left unchanged, showed good model performance for PM2.5, PM10 and $\mathrm{NO}_{2}$ (cross-validation $\mathrm{R}^{2}=77 \%, 88 \%$ and $87 \%$, respectively) and a moderate performance for PMcoarse (cross-validation $\mathrm{R}^{2}=57 \%$ ). Evaluation of ESCAPE LUR estimates was conducted by comparing model predictions to the UK's Automatic Urban and Rural Network monitoring data [17]. The LUR $\mathrm{NO}_{2}$ model predicted measured concentrations reasonably well $\left(\mathrm{R}^{2}=0.67\right)$, while the LUR PM10 model predicted concentrations moderately well in central and southern areas of the UK $\left(R^{2}=0.53\right)$, but $R^{2}$ values were $<0.5$ in northern England or Scotland, so these areas were dropped from PM analyses [18].

\section{Confounder and effect modifier variables}

Sociodemographic and behavioural confounders and potential effect modifiers were identified a priori through literature search. Age was derived from birth date and date of baseline assessment. Body mass index (BMI) was constructed from measured height and weight. The UK Biobank five-level before-tax household income variable was dichotomised to "less than" or "equal to or above" GBP 31000 categories, 
being closest to the UK median gross household income in 2009/2010 (GBP 27789) [19]. Educational attainment was defined as "lower vocational qualification or less" versus "higher vocational qualification or more". The smoking status variable classified participants as never, previous or current tobacco smokers. Passive smoking exposure was defined as exposure $\geqslant 1 \mathrm{~h} \cdot \mathrm{week}^{-1}$ to other people's tobacco smoke at home. Asthma status was based on a self-reported doctor diagnosis of asthma. Lastly, participants reporting current employment for one of 14 jobs associated with an increased risk (prevalence ratio $\geqslant 1.30$ ) for COPD identified by De MatTeIs et al. [11] (supplementary table S2) were classified as having an "at-risk" occupation.

\section{Statistical analyses}

We performed descriptive analyses followed by cross-sectional linear regression analyses for lung function and logistic regression analyses for COPD. The associations between baseline FEV1, FVC and FEV1/FVC ratio and annual average air pollutant concentrations at place of residence were adjusted for age, age-squared, sex, height, BMI $\left(\mathrm{kg} \cdot \mathrm{m}^{-2}\right)$, household income, education level, smoking status and passive smoking exposure. Associations for COPD (FEV1/FVC $<$ LLN) at baseline were adjusted for age, sex, BMI, household income, education level, smoking status and passive smoking exposure. In order to allow direct comparison with previous ESCAPE studies on air pollution and lung function impairment and COPD [5, 6, 20], all associations were reported per $5 \mu \mathrm{g} \cdot \mathrm{m}^{-3}$ increase of $\mathrm{PM} 2.5$ and PMcoarse and per $10 \mu \mathrm{g} \cdot \mathrm{m}^{-3}$ increase of $\mathrm{PM} 10$ and $\mathrm{NO}_{2}$. To allow interquartile range (IQR) comparison of pollutant effects in the UK Biobank population, results were also reported per IQR increase of air pollutant. Sensitivity analyses were conducted by restricting analyses to individuals living at the same address for $\geqslant 10$ years, to minimise exposure misclassification. In addition, we investigated whether pro-inflammatory characteristics modified the relationship between $\mathrm{PM} 2.5$ and $\mathrm{NO}_{2}$ air pollution and lung function and COPD. Stratified analyses were conducted for sex (male versus female), age ( $<65$ versus $\geqslant 65$ years), obesity (non-obese versus obese), smoking status (never versus current or past smoker), household income (<GBP 31000 versus $\geqslant G B P 31000$ ), asthma status (never versus ever diagnosed) and occupational status (at-risk versus not at-risk occupation) (supplementary table S2). Lastly, we calculated attributable fraction of COPD prevalence due to PM2.5 exposure above World Health Organization (WHO) air quality guideline levels $\left(>10 \mu \mathrm{g} \cdot \mathrm{m}^{-3}\right)$, current/past smoking and passive smoking exposure at home.

All statistical analyses were limited to participants with complete exposure and model covariate data and were performed in R Statistical Software, version 3.4.4 [21].

\section{Exclusions and missing data}

Study population, exclusions, and missing data are outlined in figure 1. Of the 502655 UK Biobank participants, 36 had withdrawn from the cohort prior to beginning analyses. 48818 participants had not completed spirometry tests, and an additional 67823 participants were excluded due to invalid spirometry measures $(n=59850)$ or having smoked or used an inhaler within an hour of lung function test $(n=7973)$, resulting in 385978 participants with valid FEV1 and FVC measures. 82091 participants had missing data for at least one covariate in fully adjusted models, leaving 303887 participants with complete covariate data and valid lung function measures. The COPD outcome variable was available for 303183 participants, as 704 individuals had no data for the ethnicity variable used to calculate the LLN threshold. After excluding participants with missing air pollution metrics, our final samples for lung function analyses were 299537 ( $\mathrm{NO}_{2}$ population) and 278228 (PM population). COPD analyses included 298848 and 277567 participants for $\mathrm{NO}_{2}$ and $\mathrm{PM}$ populations, respectively.

\section{Results}

Characteristics for participants with complete data in fully adjusted lung function models and for excluded participants due to incomplete data are presented in table 1. The mean age of participants with complete data was 56 years and $~ 53 \%$ of participants were female. The majority of participants were overweight $(43 \%)$ or obese $(24 \%)$, had higher education qualifications $(48 \%)$ and came from households earning more than GPB 31000 annually (55\%). Three out of five participants were lifetime nonsmokers, only 3\% were current smokers and $5 \%$ reported exposure to tobacco smoke at home. $\sim 11 \%$ of study subjects had been diagnosed with asthma and $2 \%$ were currently employed in an occupation associated with an increased COPD risk. Lastly, LLN-defined COPD prevalence was $7 \%$ in our final sample. Significant differences between individuals with complete data and those with incomplete data $(n=203082)$ were found for all variables, except asthma status. Notably, the incomplete data subset had a considerably lower percentage of individuals with higher educational qualifications (38\% versus 48\%) and from higher income households ( $42 \%$ versus 55\%), and higher proportions of current smokers (22\% versus $3 \%$ ) and individuals in occupations at risk of COPD (4\% versus $2 \%)$. 


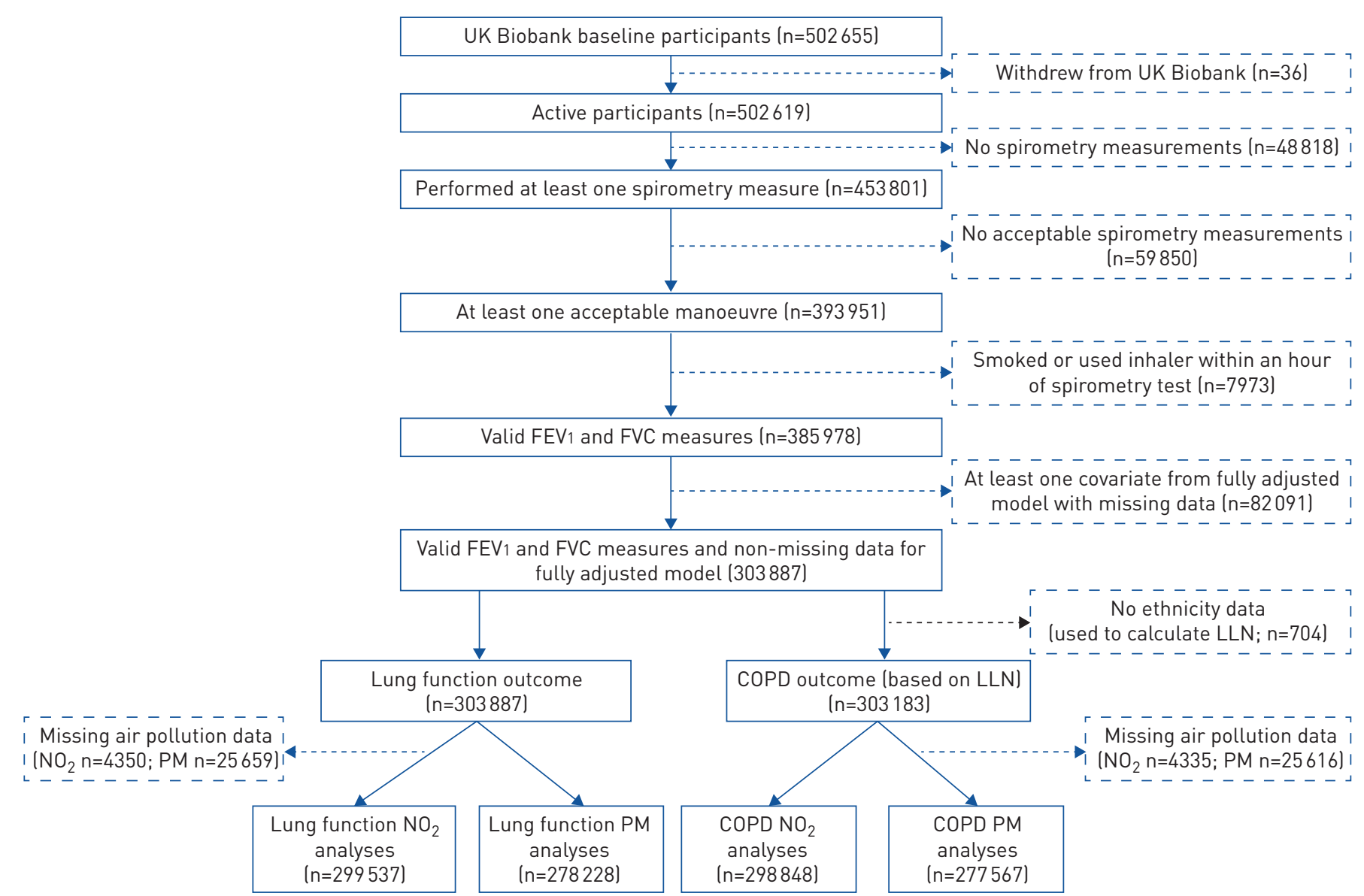

FIGURE 1 Study population, exclusions and missing data. FEV1: forced expiratory volume in 1 s; FVC: forced vital capacity; LLN: lower limit of normal; COPD: chronic obstructive pulmonary disease; $\mathrm{NO}_{2}$ : nitrogen dioxide; PM: particulate matter.

Table 2 shows the distribution of residential ambient air pollution concentrations. Mean \pm SD annual estimates of PM2.5, PM10, PMcoarse and $\mathrm{NO}_{2}$ were $9.94 \pm 1.04 \mu \mathrm{g} \cdot \mathrm{m}^{-3}, 16.18 \pm 1.90 \mu \mathrm{g} \cdot \mathrm{m}^{-3}, 6.41 \pm 0.90 \mu \mathrm{g} \cdot \mathrm{m}^{-3}$ and $26.31 \pm 7.49 \mu \mathrm{g} \cdot \mathrm{m}^{-3}$, respectively. $\mathrm{NO}_{2}$ concentrations were highly correlated with $\mathrm{PM} 2.5(\mathrm{r}=0.87)$, but less so with other PM metrics. PM10 and PMcoarse were also highly correlated ( $\mathrm{r}=0.81$ ).

Higher exposure to all pollutants showed significant associations with lower lung function (table 3 ). In adjusted models, a $5 \mu \mathrm{g} \cdot \mathrm{m}^{-3}$ increase in PM2.5 exposure was associated with lower FEV1 $(-83.13 \mathrm{~mL}$, 95\% CI $-92.50--73.75 \mathrm{~mL})$, FVC $(-62.62 \mathrm{~mL}, 95 \% \mathrm{CI}-73.91--51.32 \mathrm{~mL})$ and $\mathrm{FEV} 1 / \mathrm{FVC}$ ratio $(-9.68,95 \%$ $\mathrm{CI}-10.81--8.56)$. For each $10 \mu \mathrm{g} \cdot \mathrm{m}^{-3}$ increase in $\mathrm{NO}_{2}$, lower FEV1 $(-33.85 \mathrm{~mL}, 95 \% \mathrm{CI}-36.34--31.36$ $\mathrm{mL})$, FVC $(-33.47 \mathrm{~mL}, 95 \% \mathrm{CI}-36.47--30.46 \mathrm{~mL})$ and FEV1/FVC ratio $(-2.27,95 \% \mathrm{CI}-2.57--1.96)$ were observed. Furthermore, results showed negative associations between PM10 and PMcoarse concentrations and lung function, with stronger effects on FVC than FEV1. The FEV1/FVC ratio showed no association with ambient PM10 exposure and a small positive association with PMcoarse (1.34, 95\% CI 0.04-2.63, per $\left.10 \mu \mathrm{g} \cdot \mathrm{m}^{-3}\right)$. In the main analyses for COPD prevalence, a significant association was observed for PM2.5 (OR 1.52, 95\% CI 1.42-1.62, per $5 \mu \mathrm{g} \cdot \mathrm{m}^{-3}$ ), PM10 (1.08, 95\% CI 1.00-1.16, per $\left.10 \mu \mathrm{g} \cdot \mathrm{m}^{-3}\right)$ and $\mathrm{NO}_{2}\left(1.12,95 \% \mathrm{CI} 1.10-1.14\right.$, per $10 \mu \mathrm{g} \cdot \mathrm{m}^{-3}$ ), but not for PMcoarse (table 4). Associations per IQR increase in exposure are presented in supplementary tables S3 (for lung function) and S4 (for COPD). When compared to associations with smoking status, lower levels of FEV1 observed per $5 \mu \mathrm{g} \cdot \mathrm{m}^{-3}$ increase in PM2.5 represented $65 \%$ and $29 \%$ of FEV1 loss associated with being a former and current smoker, respectively (supplementary table S5). Furthermore, the odds of COPD per $5 \mu \mathrm{g} \cdot \mathrm{m}^{-3}$ increment of PM2.5 was equivalent to more than half the odds of COPD associated with passive smoking exposure at home (supplementary table S5). Sensitivity analyses restricted to those who had lived in the same place for the past 10 years did not substantially change lung function or COPD associations (supplementary tables S6 and S7). Finally, attributable fraction of COPD prevalence for residential ambient PM2.5 exposure above WHO guidelines was almost half (5.6\%) that of current/past tobacco smoking (12.1\%) in the cohort and over four times that of passive smoking exposure at home (1.2\%). 
TABLE 1 Population characteristics

\begin{tabular}{|c|c|c|c|c|}
\hline & $\begin{array}{l}\text { Lung function (FEV } 1 \\
\text { and } \mathrm{FVC} \text { ) and } \mathrm{NO}_{2} \\
\text { population" }\end{array}$ & $\begin{array}{l}\text { Lung function } \\
\text { (FEV } 1 \text { and } F V C \text { ) and PM } \\
\text { population }\end{array}$ & $\begin{array}{l}\text { Excluded from analyses } \\
\text { due to incomplete data } \\
\text { (for lung function and } \\
\mathrm{NO}_{2} \text { population) }\end{array}$ & $\begin{array}{c}\text { Difference } \\
\text { p-value }\end{array}$ \\
\hline Subjects & 299537 & 278228 & 203082 & \\
\hline \multicolumn{5}{|l|}{ Sex } \\
\hline Male & 47.1 (140977) & 47.2 (131 257) & 43.4 (88 187) & $<0.001$ \\
\hline \multicolumn{5}{|l|}{ Age } \\
\hline$<65$ years & 83.2 (249067) & 83.1 (231 221) & $77.6(157526)$ & $<0.001$ \\
\hline$\geqslant 65$ years & $16.8(50470)$ & $16.9(47007)$ & $22.4(45556)$ & \\
\hline BMI $\mathbf{k g} \cdot \mathrm{m}^{-2}$ & $27.4 \pm 4.68$ & $27.4 \pm 4.69$ & $27.6 \pm 4.97$ & $<0.001$ \\
\hline Missing data & & & 3105 & \\
\hline \multicolumn{5}{|l|}{ BMI } \\
\hline Normal $\left(<25 \mathrm{~kg} \cdot \mathrm{m}^{-2}\right)$ & 33.3 (99 832) & $33.3(92673)$ & 32.7 (65350) & $<0.001$ \\
\hline A-level, 0-level or CSEs & $51.3(153657)$ & $51.9(144504)$ & $61.7(119076)$ & $<0.001$ \\
\hline $\begin{array}{l}\text { College, university, NVQ or } \\
\text { other professional qualifications }\end{array}$ & $48.7(145880)$ & $48.1(133724)$ & $38.3(73864)$ & \\
\hline Missing data & & & 10142 & \\
\hline \multicolumn{5}{|l|}{ Household income } \\
\hline$<$ GPB 31000 & $44.2(132527)$ & $44.6(124097)$ & $57.9(72891)$ & $<0.001$ \\
\hline$\geqslant$ GBP 31000 & $55.8(167010)$ & $55.4(154131)$ & 42.1 (52993) & \\
\hline Missing data & & & 77198 & \\
\hline \multicolumn{5}{|l|}{ Smoking status } \\
\hline Never-smoker & $59.0(176817)$ & $58.8(163686)$ & 48.4 (96773) & $<0.001$ \\
\hline Former smoker & 38.1 (114249) & $38.3(106658)$ & $29.4(58842)$ & \\
\hline Current smoker & $2.8(8471)$ & $2.8(7884)$ & $22.2(44515)$ & \\
\hline Missing data & & & 2952 & \\
\hline \multicolumn{5}{|l|}{$\begin{array}{l}\text { Passive smoking exposure at } \\
\text { home }\end{array}$} \\
\hline Missing data & 229 & 217 & 1914 & \\
\hline \multicolumn{5}{|l|}{ Occupational status } \\
\hline Non-"at-risk" occupation & $98.2(206506)$ & $98.2(192826)$ & $96.4(112765)$ & $<0.001$ \\
\hline "At-risk" occupation & 1.8 (3724) & 1.8 (3552) & $3.6(4165)$ & \\
\hline Missing data & 89307 & 81850 & 86152 & \\
\hline FEV 1 L & $2.9 \pm 0.78$ & $2.9 \pm 0.78$ & $2.6 \pm 0.77$ & $<0.001$ \\
\hline Missing data & & & 116641 & \\
\hline FVC L & $3.8 \pm 1.00$ & $3.8 \pm 1.00$ & $3.5 \pm 0.98$ & $<0.001$ \\
\hline Missing data & & & 116641 & \\
\hline FEV $1 / F V C$ & $0.8 \pm 0.07$ & $0.8 \pm 0.07$ & $0.8 \pm 0.08$ & $<0.001$ \\
\hline Missing data & & & 116641 & \\
\hline \multicolumn{5}{|l|}{ COPD } \\
\hline No & 92.7 (276948) & 92.6 (257 089) & $87.9(74762)$ & $<0.001$ \\
\hline Yes & $7.3(21900)$ & $7.4(20478)$ & $12.1(10267)$ & \\
\hline Missing data & 689 & 661 & 118053 & \\
\hline
\end{tabular}

Data are presented as $\mathrm{n}, \%(\mathrm{n})$ or mean $\pm \mathrm{SD}$, unless otherwise stated. $\mathrm{FEV} 1$ : forced expiratory volume in $1 \mathrm{~s}$; FVC: forced vital capacity; $\mathrm{NO}_{2}$ : nitrogen dioxide; PM: particulate matter; BMI: body mass index; CSE: Certificate of Secondary Education; NVQ: National Vocational Qualification; COPD: chronic obstructive pulmonary disease. \#: descriptive statistics shown are for participants with complete data for FEV1 and $\mathrm{FVC}$, age, sex, $\mathrm{BMI}$, education level, household income, smoking status, passive smoking exposure at home and residential $\mathrm{NO}_{2}$ exposure; ๆ: descriptive statistics shown are for participants with complete data for FEV1 and FVC, age, sex, BMI, education level, household income, smoking status, passive smoking exposure at home and residential PM exposure. 
TABLE 2 Pollutant descriptive statistics and correlation matrix

\begin{tabular}{|c|c|c|c|c|c|c|c|c|c|}
\hline \multirow[t]{2}{*}{ 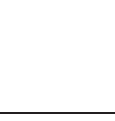 } & \multirow[t]{2}{*}{ Subjects $n$} & \multirow[t]{2}{*}{ Mean $\pm \mathrm{sD} \mu \mathrm{g} \cdot \mathrm{m}^{-3}$} & \multirow[t]{2}{*}{ Minimum $\mu \mathrm{g} \cdot \mathrm{m}^{-3}$} & \multirow[t]{2}{*}{ Maximum $\mu \mathrm{g} \cdot \mathrm{m}^{-3}$} & \multirow[t]{2}{*}{ IQR $\mu \mathrm{g} \cdot \mathrm{m}^{-3}$} & \multicolumn{4}{|c|}{ Pearson correlation coefficients } \\
\hline & & & & & & PM2.5 & PM10 & PMcoarse & $\mathrm{NO}_{2}$ \\
\hline PM2.5 & 278228 & $9.94 \pm 1.04$ & 8.17 & 19.89 & 1.27 & 1 & 0.53 & 0.21 & 0.87 \\
\hline PMcoarse & 278228 & $6.41 \pm 0.90$ & 5.57 & 12.82 & 0.77 & & & 1 & 0.19 \\
\hline $\mathrm{NO}_{2}$ & 299537 & $26.31 \pm 7.49$ & 12.93 & 108.49 & 9.70 & & & & 1 \\
\hline
\end{tabular}

IQR: interquartile range; PM2.5: fine particulate matter with a 50\% cut-off aerodynamic diameter <2.5 $\mu$ m; PM10: particulate matter with a $50 \%$ cut-off aerodynamic diameter $<10 \mu \mathrm{m}$; PMcoarse: coarse particulate matter with diameter $2.5-10 \mu \mathrm{m}_{;} \mathrm{NO}_{2}$ : nitrogen dioxide. ${ }^{\#}$ : descriptive statics shown are for participants with complete data for forced expiratory volume in $1 \mathrm{~s}$, forced vital capacity, age, sex, body mass index, education level, household income, smoking status and passive smoking exposure at home.

Results of PM2.5 and $\mathrm{NO}_{2}$ subgroup analyses for lung function and COPD are shown in tables 5 and 6, respectively. FEV1-stratified analyses showed stronger $\mathrm{PM} 2.5$ and $\mathrm{NO}_{2}$ associations among males, participants from lower income households and individuals with at-risk occupations. The same effect modification patterns were observed for FVC-stratified analyses, with never-smokers showing significantly lower FVC per $\mathrm{PM} 2.5$ and $\mathrm{NO}_{2}$ increase. Individuals from lower-income households had approximately twice as low FEV1 and FVC levels compared to higher-income participants and individuals with at-risk for COPD occupations showed three-fold lower FEV1 and FVC levels compared to individuals not in these occupations, per unit increase in $\mathrm{PM}_{2.5}$ or $\mathrm{NO}_{2}$ (table 5). Age, obesity, smoking status and household income, but not at-risk occupations modified the relationship between the FEV1/FVC ratio and PM2.5 and $\mathrm{NO}_{2}$, with stronger adverse associations for older, obese, current/past smokers and lower-income individuals. In COPD subgroup analyses (table 6), $\mathrm{PM} 2.5$ and $\mathrm{NO}_{2}$ associations were stronger among obese, lower income and non-asthmatic participants. Again, household income especially influenced the exposure-outcome relationship, with over three times stronger associations between COPD and each pollutant among lower- compared to higher-income individuals.

\section{Discussion}

Ambient concentrations of particulate matter and $\mathrm{NO}_{2}$ air pollution were associated with lower lung function and increased COPD prevalence in this very large UK cohort. Given the size of the study, we were able to investigate interactions, finding evidence for effect modification, with larger impacts of air pollution on 1) lung function in males, individuals from lower-income households and individuals with at-risk occupations; and 2) COPD in obese, lower-income and non-asthmatic participants.

Lung function is a good indicator of respiratory morbidity and mortality, especially among COPD patients [22]. Given an average FEV1 loss of $32-46 \mathrm{~mL} \cdot \mathrm{year}^{-1}$ after the age of 30 years [12], the associations per $5 \mu \mathrm{g} \cdot \mathrm{m}^{-3}$ exposure of PM2.5 found in our study are approximately equivalent to an additional 2 years of normal loss of lung function in healthy individuals if results in this cross-sectional study are confirmed in future longitudinal follow-up. We found significant reductions on lung function, even at a relatively low levels of ambient PM2.5, thereby echoing the need for more actions to be taken to control air pollution [23].

TABLE 3 Associations of lung function and ambient air pollution exposure ${ }^{\#}$

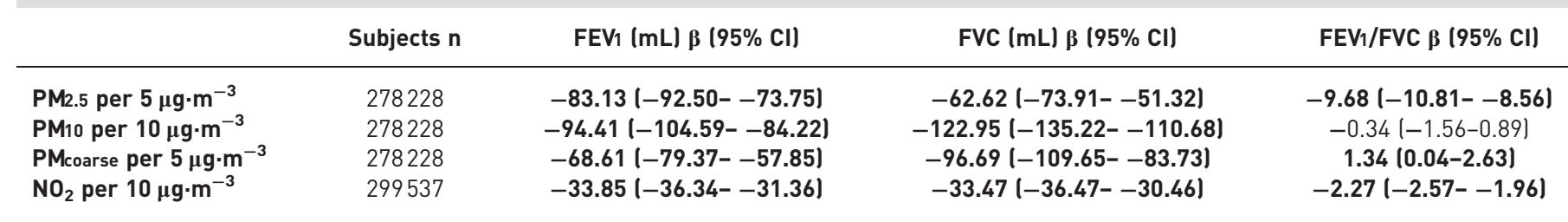

Bold type represents statistical significance. $F E V_{1}$ : forced expiratory volume in $1 \mathrm{~s}$; FVC: forced vital capacity; PM2.5: fine particulate matter with a $50 \%$ cut-off aerodynamic diameter $<2.5 \mu \mathrm{m}$; PM10: particulate matter with a 50\% cut-off aerodynamic diameter $<10 \mu \mathrm{m}$; PMcoarse: coarse particulate matter with diameter 2.5-10 $\mu \mathrm{m} ; \mathrm{NO}_{2}$ : nitrogen dioxide. \#: adjusted for age (continuous), age-squared, sex, height, body mass index $\left(\mathrm{kg} \cdot \mathrm{m}^{-2}\right)$, household income $(<\mathrm{GBP} 31000 / \geqslant G B P 31000)$, education level (lower vocational or less/higher vocational or more), smoking status (never/former/current) and passive smoking exposure at home (none/any). 
TABLE 4 Associations of chronic obstructive pulmonary disease and ambient air pollution exposure $^{\#}$

\begin{tabular}{lcc} 
& Cases/non-cases $\mathrm{n} / \mathrm{n}$ & OR (95\% CI) \\
\hline PM2.5 per $5 \mu \mathrm{g} \cdot \mathrm{m}^{-3}$ & $20478 / 257089$ & $\mathbf{1 . 5 2}(1.42-1.62)$ \\
PM10 per $10 \mu \mathrm{g} \cdot \mathrm{m}^{-3}$ & $20478 / 257089$ & $1.08(1.00-1.16)$ \\
PMcoarse per $\mathbf{\mu g} \cdot \mathrm{m}^{-3}$ & $20478 / 257089$ & $0.99(0.91-1.07)$ \\
$\mathrm{NO}_{2}$ per $10 \mu \mathrm{g} \cdot \mathrm{m}^{-3}$ & $21900 / 276948$ & $\mathbf{1 . 1 2}(1.10-1.14)$
\end{tabular}

Bold type represents statistical significance. PM2.5: fine particulate matter with a $50 \%$ cut-off aerodynamic diameter $<2.5 \mu \mathrm{m}$; PM10: particulate matter with a 50\% cut-off aerodynamic diameter $<10 \mu \mathrm{m}$; PMcoarse: coarse particulate matter with diameter $2.5-10 \mu \mathrm{m} ; \mathrm{NO}_{2}$ : nitrogen dioxide. ${ }^{\#}$ : adjusted for age (continuous), sex, body mass index $\left(\mathrm{kg} \cdot \mathrm{m}^{-2}\right)$, household income $(<\mathrm{GBP} 31000 / \geqslant G B P 31000$ ), education level (lower vocational or less/higher vocational or more), smoking status (never/former/current) and passive smoking exposure at home (none/any).

\section{Comparison with studies using the same air pollution estimates}

The current study replicated cross-sectional analyses in ESCAPE, the previous largest European study to date, using a single cohort with $>10$-fold higher numbers and the same models to estimate air pollutant exposures $[15,16]$ and similar covariate adjustment. Findings from two ESCAPE meta-analyses $[5,6]$ and from a Dutch study using ESCAPE air pollution estimates [20] are presented in figure 2. Our large sample size resulted in much smaller confidence intervals, with more statistically significant results and stronger evidence of an adverse effect of air pollution (figure 2). We found stronger (more negative) effects on lung function than in the studies by ADAM et al. [5] or DE JONG et al. [20] for each of the four air pollutants studied (PM2.5, PM10, PMcoarse, $\mathrm{NO}_{2}$ ). For COPD, our confidence intervals were much tighter than (but overlapped with) those in the study conducted by SCHIKOwsKi et al. [6], but unlike that study, we found significant associations with both $\mathrm{PM} 2.5$ and $\mathrm{NO}_{2}$.

The mean and range of estimated annual $\mathrm{NO}_{2}$ concentrations in our study were similar to those of studies included in the original ESCAPE meta-analyses [5, 6], whereas mean PM concentrations were generally lower in our study, with the exception of the British National Survey of Health and Development, which were comparable (supplementary tables S8 and S9). The range of air pollutant concentrations used in DE JONG et al. [20] was smaller than in our own study (supplementary table S10). Using similar air pollution models to those used in past ESCAPE studies means that differences in lung function and COPD associations are less likely to be due to differences in exposure estimates [24]. However, given that the original ESCAPE meta-analyses by ADAm et al. [5] and SCHIKоwsKi et al. [6] back-extrapolated air pollution estimates to date of lung function measurement by up to two decades for some participating cohorts, the larger effect size seen in our study may in part relate to reduced air pollution exposure misclassification. Finally, the same spirometers and spirometry protocols were applied in UK Biobank, whereas this was not the case across original ESCAPE studies. This may have also contributed to more precise estimates in our study.

\section{Comparison with studies using other air pollution estimates}

Our results are consistent with the small number of studies investigating PM10, PM2.5 and $\mathrm{NO}_{2}$ in relation to lung function, but few studies have investigated PMcoarse. In a study of UK residents, ForbEs et al. [25] reported comparable results for $\mathrm{FEV}_{1}$, showing a $92 \mathrm{~mL}$ and $22 \mathrm{~mL}$ decrease per $10 \mu \mathrm{g} \cdot \mathrm{m}^{-3}$ increase in PM10 and $\mathrm{NO}_{2}$, respectively. A study of 9651 healthy never-smokers in the Swiss Study of Air Pollution and Lung Disease in Adults (SAPALDIA) also found negative effects of both $\mathrm{NO}_{2}$ and PM10 exposure on FEV1 and FVC [26]. An analysis of Framingham Heart Study participants by RiCE et al. [3] found significant negative associations of residential PM2.5 exposure with both FEV1 and FVC levels, and a faster decline in lung function levels.

Our findings of associations between PM2.5 and airflow obstruction and COPD are consistent with a recent study of 285000 Taiwan residents showing significant associations between ambient PM2.5 and reduced $\mathrm{FEV} 1 / \mathrm{FVC}$ ratio and risk of COPD [4], and with findings from the German Study on the Influence of Air pollution on Lung, Inflammation and Aging (SALIA) cohort in relation to $\mathrm{NO}_{2}$ and FEV1/FVC ratio and spirometrically defined COPD [27]. A separate analysis of SALIA participants also showed a decline in COPD with reduced $\mathrm{NO}_{2}$ concentrations [28]. However, in contrast to our findings, no associations of $\mathrm{NO}_{2}$ or PM2.5 exposure with FEV1/FVC were reported by Forbes et al. [25] or RICE et al. [3]. 
TABLE 5 Lung function subgroup analyses for fine particulate matter with diameter $<2.5 \mu \mathrm{m}(\mathrm{PM} 2.5)$ and nitrogen dioxide $\left(\mathrm{NO}_{2}\right)^{\#}$

\begin{tabular}{|c|c|c|c|c|c|c|c|c|c|c|c|c|}
\hline & \multicolumn{4}{|c|}{$\mathrm{FEV}_{1} \mathrm{~mL}$} & \multicolumn{4}{|c|}{$\mathrm{FVC} \mathrm{mL}$} & \multicolumn{4}{|c|}{$\mathrm{FEV}_{1} / \mathrm{FVC}$} \\
\hline & \multicolumn{2}{|c|}{ PM2.5 per $5 \mu \mathrm{g} \cdot \mathrm{m}^{-3}$} & \multicolumn{2}{|c|}{$\mathrm{NO}_{2}$ per $10 \mu \mathrm{g} \cdot \mathrm{m}^{-3}$} & \multicolumn{2}{|c|}{$\mathrm{PM}_{2.5}$ per $5 \mu \mathrm{g} \cdot \mathrm{m}^{-3}$} & \multicolumn{2}{|c|}{$\mathrm{NO}_{2}$ per $10 \mu \mathrm{g} \cdot \mathrm{m}^{-3}$} & \multicolumn{2}{|c|}{ PM2.5 per $5 \mu \mathrm{g} \cdot \mathrm{m}^{-3}$} & \multicolumn{2}{|c|}{$\mathrm{NO}_{2}$ per $10 \mu \mathrm{g} \cdot \mathrm{m}^{-3}$} \\
\hline & $\beta(95 \% \mathrm{Cl})$ & $\begin{array}{c}\text { Interaction } \\
p \text {-value }\end{array}$ & $\beta(95 \% \mathrm{Cl})$ & $\begin{array}{c}\text { Interaction } \\
\text { p-value }\end{array}$ & $\beta(95 \% \mathrm{Cl})$ & $\begin{array}{c}\text { Interaction } \\
\text { p-value }\end{array}$ & $\beta(95 \% \mathrm{Cl})$ & $\begin{array}{l}\text { Interaction } \\
\text { p-value }\end{array}$ & $\beta(95 \% \mathrm{Cl})$ & $\begin{array}{l}\text { Interaction } \\
\text { p-value }\end{array}$ & $\beta(95 \% \mathrm{Cl})$ & $\begin{array}{c}\text { Interaction } \\
\text { p-value }\end{array}$ \\
\hline Sex & & $<0.001$ & & $<0.001$ & & $<0.001$ & & $<0.001$ & & 0.928 & & 0.883 \\
\hline Male & $\begin{array}{c}-102.32 \\
(-118.16--86.48)\end{array}$ & & $\begin{array}{c}-41.22 \\
(-45.44--37.00)\end{array}$ & & $\begin{array}{c}-78.48 \\
(-97.42--59.54)\end{array}$ & & $\begin{array}{c}-40.85 \\
(-45.89--35.81)\end{array}$ & & $\begin{array}{c}-9.52 \\
(-11.25--7.80)\end{array}$ & & $\begin{array}{c}-2.27 \\
(-2.73--1.80)\end{array}$ & \\
\hline Female & $\begin{array}{c}-68.14 \\
(-78.68--57.59)\end{array}$ & & $\begin{array}{c}-28.01 \\
(-30.82--25.21)\end{array}$ & & $\begin{array}{c}-50.47 \\
(-63.28--37.67)\end{array}$ & & $\begin{array}{c}-27.66 \\
(-31.06--24.26)\end{array}$ & & $\begin{array}{c}-9.79 \\
(-11.26--8.32)\end{array}$ & & $\begin{array}{c}-2.25 \\
(-2.65--1.86)\end{array}$ & \\
\hline Age & & 0.574 & & 0.113 & & 0.187 & & 0.014 & & $<0.001$ & & $<0.001$ \\
\hline$<65$ years & $\begin{array}{c}-83.63 \\
(-93.85--73.40)\end{array}$ & & $\begin{array}{c}-32.55 \\
(-37.27--31.83)\end{array}$ & & $\begin{array}{c}-65.06 \\
(-77.40--52.71)\end{array}$ & & $\begin{array}{c}-34.86 \\
(-38.15--31.58)\end{array}$ & & $\begin{array}{c}-8.92 \\
(-10.11--7.73)\end{array}$ & & $\begin{array}{c}-2.04 \\
(-2.36--1.72)\end{array}$ & \\
\hline$\geqslant 65$ years & $\begin{array}{c}-85.32 \\
(-108.62--62.01)\end{array}$ & & $\begin{array}{c}-31.64 \\
(-37.82--25.47)\end{array}$ & & $\begin{array}{c}-54.05 \\
(-81.85--26.25)\end{array}$ & & $\begin{array}{c}-27.41 \\
(-34.78--20.05)\end{array}$ & & $\begin{array}{c}-13.73 \\
(-16.91--10.54)\end{array}$ & & $\begin{array}{c}-3.50 \\
(-4.35--2.65)\end{array}$ & \\
\hline Obesity & & 0.068 & & 0.003 & & 0.460 & & 0.082 & & 0.005 & & 0.005 \\
\hline Non-obese & $\begin{array}{c}-78.68 \\
(-89.31--68.04)\end{array}$ & & $\begin{array}{c}-31.69 \\
(-34.51--28.87)\end{array}$ & & $\begin{array}{c}-58.93 \\
(-71.78--46.08)\end{array}$ & & $\begin{array}{c}-31.65 \\
(-35.05--28.24)\end{array}$ & & $\begin{array}{c}-9.07 \\
(-10.36--7.79)\end{array}$ & & $\begin{array}{c}-2.07 \\
(-2.41--1.73)\end{array}$ & \\
\hline Obese & $\begin{array}{c}-95.53 \\
(-115.24--75.82)\end{array}$ & & $\begin{array}{c}-40.36 \\
(-45.68--35.04)\end{array}$ & & $\begin{array}{c}-76.78 \\
(-100.30--53.27)\end{array}$ & & $\begin{array}{c}-40.78 \\
(-47.12--34.45)\end{array}$ & & $\begin{array}{c}-10.99 \\
(-13.32--8.67)\end{array}$ & & $\begin{array}{c}-2.61 \\
(-3.24--1.98)\end{array}$ & \\
\hline Smoking status & & 0.388 & & $<0.001$ & & $<0.001$ & & $<0.001$ & & $<0.001$ & & $<0.001$ \\
\hline Never-smoker & $\begin{array}{c}-84.49 \\
(-96.74--72.25)\end{array}$ & & $\begin{array}{c}-38.11 \\
(-41.37--34.85)\end{array}$ & & $\begin{array}{c}-76.56 \\
(-91.51--61.60)\end{array}$ & & $\begin{array}{c}-41.89 \\
(-45.87--37.91)\end{array}$ & & $\begin{array}{c}-6.91 \\
(-8.35--5.47)\end{array}$ & & $\begin{array}{c}-1.61 \\
(-2.00--1.23)\end{array}$ & \\
\hline Current or past & -87.08 & & -30.42 & & -49.66 & & -24.42 & & -13.80 & & $\begin{array}{l}-3.31 \\
-70\end{array}$ & \\
\hline smoker & $(-101.61--72.55)$ & & $(-34.28--26.56)$ & & $(-66.87--32.46)$ & & $(-28.99--19.85)$ & & $(-15.59--12.00)$ & & $(-3.79--2.83)$ & \\
\hline $\begin{array}{c}\text { Household } \\
\text { income }\end{array}$ & $<0.001$ & & $<0.001$ & & $<0.001$ & & $<0.001$ & & $<0.001$ & & $<0.001$ & \\
\hline$<$ GBP 31000 & $\begin{array}{c}-78.85 \\
(-93.56--64.13)\end{array}$ & & $\begin{array}{c}-35.76 \\
(-39.79--31.73)\end{array}$ & & $\begin{array}{c}-95.83 \\
(-112.86--78.79)\end{array}$ & & $\begin{array}{c}-46.92 \\
(-51.58--42.25)\end{array}$ & & $\begin{array}{c}-13.70 \\
(-15.49--11.91)\end{array}$ & & $\begin{array}{c}-3.46 \\
(-3.96--2.97)\end{array}$ & \\
\hline$\geqslant$ GBP 31000 & $\begin{array}{c}-39.12 \\
(-52.30--25.94)\end{array}$ & & $\begin{array}{c}-21.81 \\
(-25.24--18.37)\end{array}$ & & $\begin{array}{c}-31.69 \\
(-46.76--16.62)\end{array}$ & & $\begin{array}{c}-22.15 \\
(-26.08--18.23)\end{array}$ & & $\begin{array}{c}-6.38 \\
(-7.82--4.95)\end{array}$ & & $\begin{array}{c}-1.41 \\
(-1.78--1.03)\end{array}$ & \\
\hline Asthma status & & 0.002 & & 0.033 & & 0.094 & & 0.319 & & 0.013 & & 0.113 \\
\hline $\begin{array}{r}\text { Never had } \\
\text { asthma }\end{array}$ & $\begin{array}{c}-84.84 \\
(-94.61--75.08)\end{array}$ & & $\begin{array}{c}-33.93 \\
(-36.53--31.33)\end{array}$ & & $\begin{array}{c}-63.17 \\
(-75.10--51.24)\end{array}$ & & $\begin{array}{c}-33.21 \\
(-36.38--30.04)\end{array}$ & & $\begin{array}{c}-9.78 \\
(-10.92--8.64)\end{array}$ & & $\begin{array}{c}-2.27 \\
(-2.57--1.96)\end{array}$ & \\
\hline $\begin{array}{l}\text { Ever had } \\
\text { asthma }\end{array}$ & $\begin{array}{c}-70.01 \\
(-99.76--40.26)\end{array}$ & & $\begin{array}{c}-33.13 \\
(-41.08--25.17)\end{array}$ & & $\begin{array}{c}-54.57 \\
(-89.32--19.81)\end{array}$ & & $\begin{array}{c}-34.12 \\
(-43.40--24.85)\end{array}$ & & $\begin{array}{c}-9.25 \\
(-13.30--5.21)\end{array}$ & & $\begin{array}{c}-2.43 \\
(-3.51--1.34)\end{array}$ & \\
\hline $\begin{array}{l}\text { Occupational } \\
\text { status }\end{array}$ & 0.001 & & $<0.001$ & & 0.002 & & $<0.001$ & & 0.431 & & 0.594 & \\
\hline Non-"at-risk" & -71.88 & & -30.88 & & -57.95 & & -32.20 & & -6.94 & & -1.57 & \\
\hline occupation & $(-83.25--60.51)$ & & $(-33.87--27.89)$ & & $(-71.67--44.24)$ & & $(-35.81--28.59)$ & & $(-8.25--5.62)$ & & $(-1.92--1.22)$ & \\
\hline $\begin{array}{l}\text { "At-risk" } \\
\text { occupation }\end{array}$ & $\begin{array}{c}-183.85 \\
(-271.13--96.56)\end{array}$ & & $\begin{array}{c}-77.71 \\
(-101.86--53.57)\end{array}$ & & $\begin{array}{c}-192.19 \\
(-296.36--88.01)\end{array}$ & & $\begin{array}{c}-91.28 \\
(-120.11--62.46)\end{array}$ & & $-9.18(-19.57-1.20)$ & & $\begin{array}{c}-1.81(-4.71- \\
1.09)\end{array}$ & \\
\hline
\end{tabular}

FEV1: forced expiratory volume in $1 \mathrm{~s}$; FVC: forced vital capacity. ${ }^{\#}$ : adjusted for age (continuous), age-squared, sex, height, body mass index (kg.m ${ }^{-2}$ ), household income (<GBP $31000 /$ $\geqslant$ GBP 31000 ), education level (lower vocational or less/higher vocational or more), smoking status (never/former/current) and passive smoking exposure at home (none/any). 
TABLE 6 Chronic obstructive pulmonary disease subgroup analyses for fine particulate matter with diameter <2.5 $\mu$ m (PM2.5) and nitrogen dioxide $\left(\mathrm{NO}_{2}\right)^{\#}$

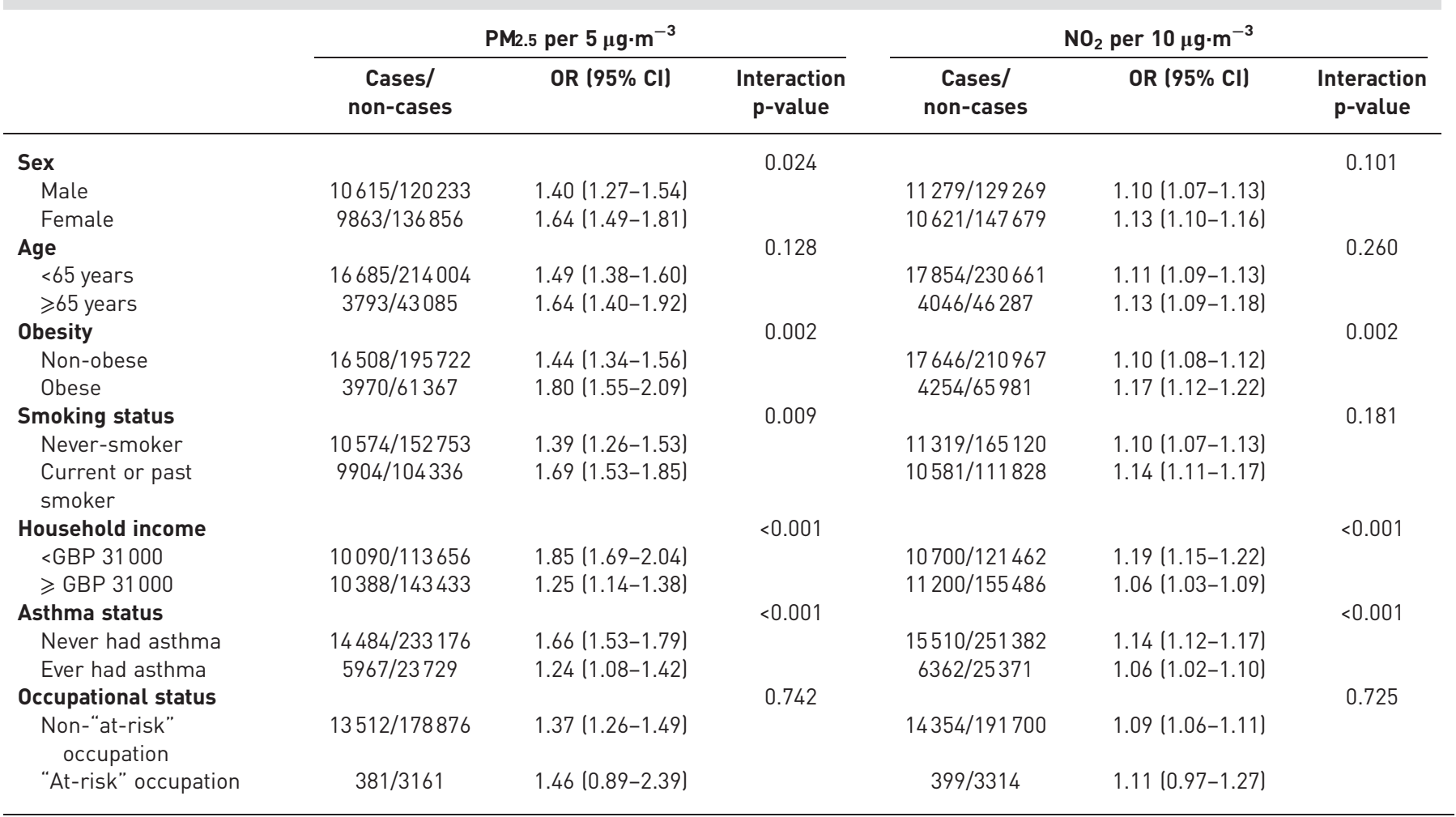

Data are presented as $\mathrm{n} / \mathrm{n}$, unless otherwise stated. ${ }^{\#}$ : adjusted for age (continuous), sex, body mass index $\left(\mathrm{kg} \cdot \mathrm{m}^{-2}\right)$, household income $(<\mathrm{GBP}$ $31000 / \geqslant G B P 31000$ ), education level (lower vocational or less/higher vocational or more), smoking status (never/former/current) and passive smoking exposure at home (none/any).

\section{Effect modifiers of air pollution}

We observed considerably stronger associations for lung function and COPD among individuals from lower-income households. The greater vulnerability of lower-income individuals to the respiratory health effects of air pollution exposure is in line with previous studies [18, 29, 30], and is probably due to numerous factors, including more childhood respiratory infections, poorer housing conditions and indoor air quality, poor nutrition and occupational exposures [31].

Our study found that occupational status in a job judged at risk of COPD to be an important effect modifier of associations between air pollution exposure and lung function, but not its associations with COPD. The latter may be due to the "healthy worker" effect, whereby those with COPD are less likely to be employed in an at-risk job; we did not have information on past occupation. Few studies are available for comparison, but the Harvard Six Cities Study found higher relative risks of death per unit of PM2.5 among individuals reporting workplace exposure to dust or fumes [32].

We observed stronger $\mathrm{PM}_{2} .5$ and $\mathrm{NO}_{2}$ associations with $\mathrm{FEV} 1$ and $\mathrm{FVC}$ among males and stronger associations between PM2.5 exposure and COPD for females. Equivocal evidence has been found regarding effect modification of sex in associations between air pollution exposure and lung function and COPD in adults [33]. In studies reporting stronger effects in males, work-related exposures leading to greater predisposition to airway disease, and more time spent outdoors potentially resulting in higher exposures for a given concentration have been suggested as potential sources of differential effects [34, 35]. Hypotheses for a larger impact of air pollution on lung health among females include more time spent at home leading to better accuracy of residential air pollution exposure assignment, as well as biological factors such as greater airway reactivity $[36,37]$.

We also found significant effect modification by obesity, with higher air pollution associations with COPD risk and reduced lung function for obese individuals, which is consistent with other studies using ESCAPE air pollution estimates $[5,20]$. Mechanistic studies have shown greater than additive effects of excess body 
UK Biobank results

PM2.5

per $5 \mu \mathrm{g} \cdot \mathrm{m}^{-3}$

$\mathrm{PM} 10$

per $10 \mu \mathrm{g} \cdot \mathrm{m}^{-3}$

PMcoarse per $5 \mu \mathrm{g} \cdot \mathrm{m}^{-3}$

$\mathrm{NO}_{2}$ per $10 \mu \mathrm{g} \cdot \mathrm{m}^{-3}$

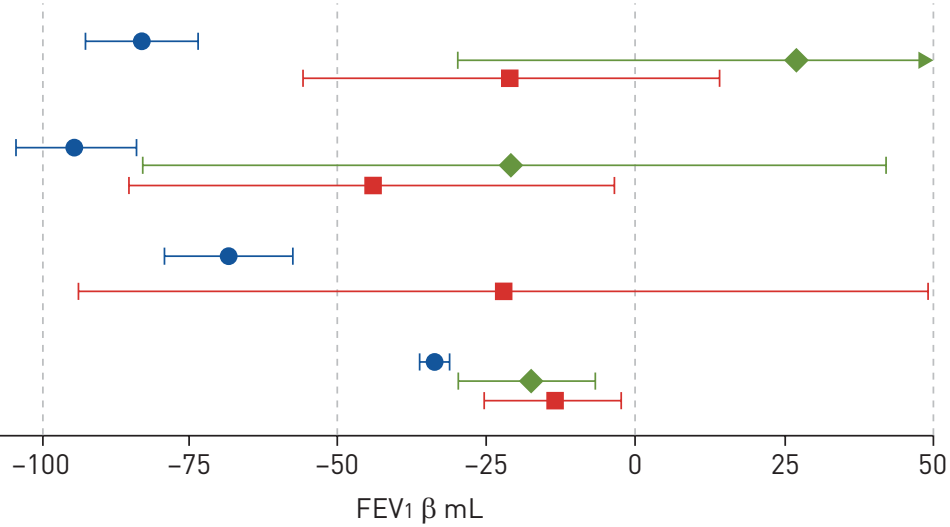

b)

Adam et al. (2014) [5] DE Jong et al. (2016) [20] • UK Biobank results

PM2.5

per $5 \mu \mathrm{g} \cdot \mathrm{m}^{-3}$

PM10

per $10 \mu \mathrm{g} \cdot \mathrm{m}^{-3}$

PMcoarse per $5 \mu \mathrm{g} \cdot \mathrm{m}^{-3}$

$\mathrm{NO}_{2}$ per $10 \mu \mathrm{g} \cdot \mathrm{m}^{-3}$

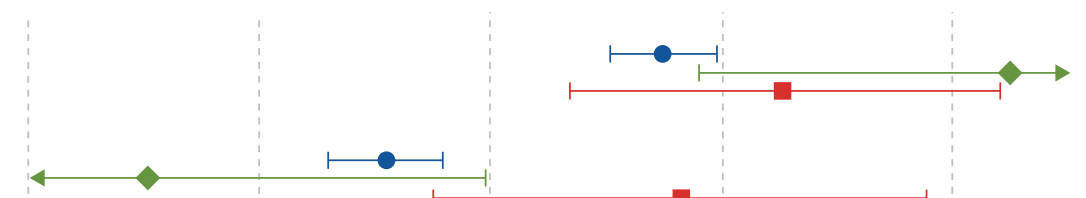

c)

- ScHIKowski et al. (2014) [6]

PM2.5

per $5 \mu \mathrm{g} \cdot \mathrm{m}^{-3}$

PM10

per $10 \mu \mathrm{g} \cdot \mathrm{m}^{-3}$

PMcoarse per $5 \mu \mathrm{g} \cdot \mathrm{m}^{-3}$

$\mathrm{NO}_{2}$ per $10 \mu \mathrm{g} \cdot \mathrm{m}^{-3}$

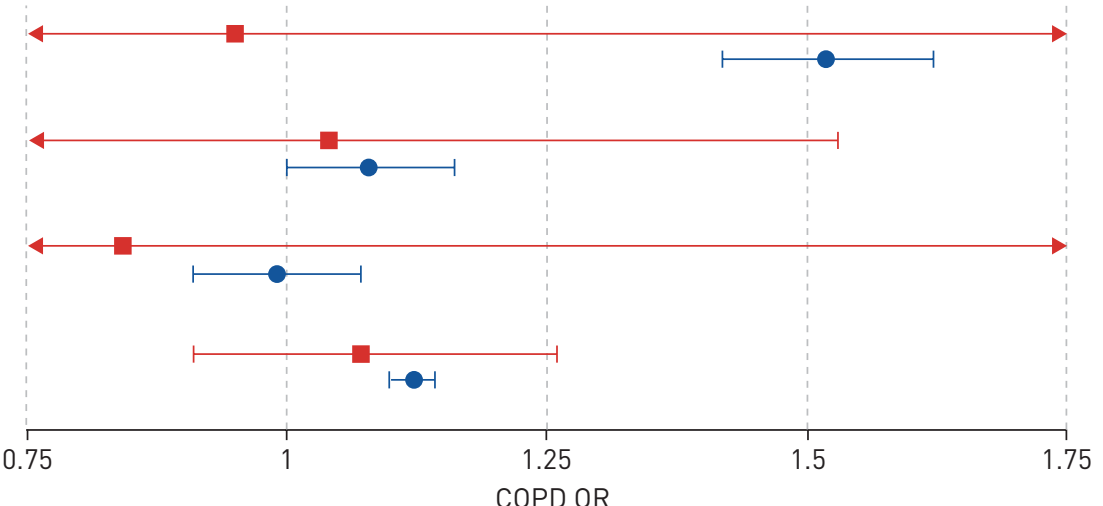

FIGURE 2 Air pollution exposure, a) forced expiratory volume in $1 \mathrm{~s}$ (FEV 1 ), b) forced vital capacity (FVC) and c) chronic obstructive pulmonary disease (COPD): comparison with other studies using European Study of Cohorts for Air Pollution Effects (ESCAPE) air pollution estimates. Cohorts included in each study: AdAM et al. [5]: European Community Respiratory Health Survey (ECRHS), French Epidemiological Study on Genetics and Environment of Asthma (EGEA), National Survey of Health and Development (NSHD), Study on the Influence of Air Pollution on Lung Function, Inflammation and Aging (SALIA) and Swiss Cohort Study on Air Pollution and Lung and Heart Diseases in Adults (SAPALDIA); DE Jong et al. [20]: Lifelines Cohort Study; ScHIKowski et al. [6]: ECRHS, NSHD, SALIA and SAPALDIA. PM2.5: fine particulate matter with a $50 \%$ cut-off aerodynamic diameter $<2.5 \mu \mathrm{m}$; PM10: particulate matter with a $50 \%$ cut-off aerodynamic diameter $<10 \mu \mathrm{m}$; PMcoarse: coarse particulate matter with diameter 2.5-10 $\mu \mathrm{m} ; \mathrm{NO}_{2}$ : nitrogen dioxide.

fat and air pollutant exposure on systemic inflammation and oxidative stress [38, 39], suggesting an enhanced response to inflammatory stimuli [39], resulting in airway damage and inflammation in obese individuals. 
Stronger negative effects of air pollution on respiratory disease among never-smokers have been reported previously $[6,8,40]$, which our analyses also found. As smoking might already reduce pulmonary function through inflammatory pathways, any additional impact of air pollution on respiratory abnormalities could be smaller or harder to detect in this subgroup.

In addition, we found that asthma status modified the associations between $\mathrm{PM} 2.5$ and $\mathrm{NO}_{2}$ and COPD prevalence, with significantly stronger associations in non-asthmatics. This may be related to treatment in asthmatics, modifying adverse impacts of air pollution or alternatively, avoidance in that asthmatics aware of impact of air pollution on symptoms may choose to live in less polluted areas.

\section{Strengths and limitations}

The large sample size of our study provided good statistical power to assess effects of air pollution, even in relatively small subgroups such as individuals in occupations with increased COPD risk. An additional strength of our study was the use of a single well-respected cohort with a rigorously defined protocol.

A potential major limitation of the study is the large number of participants with missing data for covariates included in our final regression models. This did not appear to be missing at random (therefore difficult to address using imputation), but gave us a wealthier and healthier cohort. This does not invalidate findings, but may affect generalisability. Given our findings of interactions with lower socioeconomic status individuals, we might expect this would underestimate associations of air pollution and lung function and COPD in a general population.

Another limitation is that while COPD should be classified using post-bronchodilator spirometry tests, only pre-bronchodilator measures were available, similar to the ESCAPE five-cohort analysis [5]. The extent that air pollution affects $\mathrm{FEV} 1$ and $\mathrm{FEV} 1 / \mathrm{FVC}$ ratio could potentially have been mitigated if assessed post-bronchodilator.

Common to most other ambient air pollution studies, we used place of residence to estimate air pollution exposure, which will result in exposure misclassification. Furthermore, annual air pollution estimates at recruitment address were modelled to a single year (2010), which may differ by up to 4 years from when lung function was measured. We made a reasonable assumption that the spatial contrast in air pollution exposures will have been relatively stable in the UK over these years [41], but cannot exclude the possibility of exposure misclassification. Finally, the cross-sectional relationship between air pollution and lung function and COPD demonstrated in our study show associations, but are prone to the influence of confounders and do not allow us to examine temporal patterns between air pollution exposure and respiratory outcomes. Longitudinal analyses of future follow-up data in large cohorts such as UK Biobank are needed to strengthen inferences regarding causal relationships between air pollution and respiratory disease, particularly among vulnerable subpopulations.

In conclusion, this is one of the largest analyses to date to examine associations between ambient air pollution and lung function and COPD. Air pollutant concentrations were clearly associated with lower lung function and increased COPD prevalence with higher impacts in males, individuals from lower income households, those in occupations with adverse respiratory exposures and those who were obese.

Author contributions: D. Doiron, K. de Hoogh and A.L. Hansell proposed the study; all authors contributed to development of the study design; D. Doiron conducted the statistical analyses and wrote the first draft of the paper; all authors commented on results and contributed to the manuscript.

Conflict of interest: None declared.

Support statement: This research has been conducted using the UK Biobank Resource under application number "9946". Y. Cai is supported by an MRC Early Career Research Fellowship awarded through the MRC-PHE Centre for Environment and Health (grant number MR/M501669/1).

\section{References}

1 Götschi T, Heinrich J, Sunyer J, et al. Long-term effects of ambient air pollution on lung function: a review. Epidemiology 2008; 19: 690-701.

2 Schikowski T, Mills IC, Anderson HR, et al. Ambient air pollution: a cause of COPD? Eur Respir J 2014; 43: 250-263.

3 Rice MB, Ljungman PL, Wilker EH, et al. Long-term exposure to traffic emissions and fine particulate matter and lung function decline in the Framingham Heart Study. Am J Respir Crit Care Med 2015; 191: 656-664.

4 Guo C, Zhang Z, Lau AKH, et al. Effect of long-term exposure to fine particulate matter on lung function decline and risk of chronic obstructive pulmonary disease in Taiwan: a longitudinal, cohort study. Lancet Planet Health 2018; 2: e114-e125.

5 Adam M, Schikowski T, Carsin AE, et al. Adult lung function and long-term air pollution exposure. ESCAPE: a multicentre cohort study and meta-analysis. Eur Respir J 2015; 45: 38-50.

6 Schikowski T, Adam M, Marcon A, et al. Association of ambient air pollution with the prevalence and incidence of COPD. Eur Respir J 2014; 44: 614-626. 
7 Atkinson RW, Carey IM, Kent AJ, et al. Long-term exposure to outdoor air pollution and the incidence of chronic obstructive pulmonary disease in a national English cohort. Occup Environ Med 2015; 72: 42-48.

8 Fisher JA, Puett RC, Hart JE, et al. Particulate matter exposures and adult-onset asthma and COPD in the Nurses Health Study. Eur Respir J 2016; 48: 921-924.

9 UK Biobank. Protocol for a large-scale prospective epidemiological resource. www.ukbiobank.ac.uk/wp-content/ uploads/2011/11/UK-Biobank-Protocol.pdf 2007.

10 Allen N, Sudlow C, Downey P, et al. UK Biobank: current status and what it means for epidemiology. Health Policy Technol 2012; 1: 123-126.

11 De Matteis S, Jarvis D, Hutchings S, et al. Occupations associated with COPD risk in the large population-based UK Biobank cohort study. Occup Environ Med 2016; 73: 378-384.

12 Quanjer PH, Stanojevic S, Cole TJ, et al. Multi-ethnic reference values for spirometry for the 3-95-yr age range: the global lung function 2012 equations. Eur Respir J 2012; 40: 1324-1343.

13 European Respiratory Society. Spirometry Equation Tools - R Macro. e-learning ressources. www.ers-education. org/guidelines/global-lung-function-initiative/spirometry-tools/r-macro.aspx Date last accessed: January 15, 2018. Date last updated: 2017.

14 Global Initiative for Chronic Obstructive Lung Disease (GOLD). Global Strategy for the Diagnosis, Management, and Prevention of COPD. 2016. Available from http://goldcopd.org

15 Beelen $\mathrm{R}$, Hoek G, Vienneau $\mathrm{D}$, et al. Development of $\mathrm{NO}_{2}$ and $\mathrm{NO}_{\mathrm{x}}$ land use regression models for estimating air pollution exposure in 36 study areas in Europe - the ESCAPE project. Atmos Environ 2013; 72: 10-23.

16 Eeftens M, Beelen R, de Hoogh K, et al. Development of land use regression models for PM2.5, PM2.5 absorbance, PM10 and PMcoarse in 20 European study areas; results of the ESCAPE project. Environ Sci Technol 2012; 46: $11195-11205$.

17 Gulliver J, de Hoogh K Environmental exposure assessment: modelling air pollution concentrations. In: Detels R, Gulliford M, Karim Q, Tan C, eds. Oxford Textbook of Global Health. Oxford, Oxford University Press, 2015.

18 Doiron D, de Hoogh K, Probst-Hensch N, et al. Residential air pollution and associations with wheeze and shortness of breath in adults: a combined analysis of cross-sectional data from two large european cohorts. Environ Health Perspect 2017; 125: 097025.

19 Office for National Statistics. Median Gross Income, All Households 1977 to Financial Year Ending 2016.2017.

20 de Jong K, Vonk JM, Zijlema WL, et al. Air pollution exposure is associated with restrictive ventilatory patterns. Eur Respir J 2016; 48: 1221-1224.

21 R Core Team. R: A Language and Environment for Statistical Computing. R Foundation for Statistical Computing, Vienna, 2018.

22 Young RP, Hopkins R, Eaton TE. Forced expiratory volume in one second: not just a lung function test but a marker of premature death from all causes. Eur Respir J 2007; 30: 616-622.

23 Lancet Respiratory Medicine. New strategy for clean air in the UK — is it enough? Lancet Respir Med 2019 ; 7: 187.

24 de Hoogh K, Korek M, Vienneau D, et al. Comparing land use regression and dispersion modelling to assess residential exposure to ambient air pollution for epidemiological studies. Environ Int 2014; 73: 382-392.

25 Forbes LJL, Kapetanakis V, Rudnicka AR, et al. Chronic exposure to outdoor air pollution and lung function in adults. Thorax 2009; 64: 657-663.

26 Ackermann-Liebrich U, Leuenberger P, Schwartz J, et al. Lung function and long term exposure to air pollutants in Switzerland. Study on Air Pollution and Lung Diseases in Adults (SAPALDIA) Team. Am J Respir Crit Care Med 1997; 155: 122-129.

27 Schikowski T, Sugiri D, Ranft U, et al. Long-term air pollution exposure and living close to busy roads are associated with COPD in women. Respir Res 2005; 6: 152.

28 Schikowski T, Ranft U, Sugiri D, et al. Decline in air pollution and change in prevalence in respiratory symptoms and chronic obstructive pulmonary disease in elderly women. Respir Res 2010; 11: 113.

29 Wheeler BW, Ben-Shlomo Y. Environmental equity, air quality, socioeconomic status, and respiratory health: a linkage analysis of routine data from the Health Survey for England. J Epidemiol Community Health 2005; 59: 948-954.

30 Forastiere F, Stafoggia M, Tasco C, et al. Socioeconomic status, particulate air pollution, and daily mortality: differential exposure or differential susceptibility. Am J Ind Med 2007; 50: 208-216.

31 Hegewald MJ, Crapo RO. Socioeconomic status and lung function. Chest 2007; 132: 1608-1614.

32 Krewski D, Burnett RT, Goldberg M, et al. Reanalysis of the Harvard Six Cities Study, part ii: sensitivity analysis. Inhal Toxicol 2005; 17: 343-353.

33 Clougherty JE. A growing role for gender analysis in air pollution epidemiology. Environ Health Perspect 2010; 118: $167-176$.

34 Abbey DE, Burchette RJ, Knutsen SF, et al. Long-term particulate and other air pollutants and lung function in nonsmokers. Am J Respir Crit Care Med 1998; 158: 289-298.

35 Galizia A, Kinney PL. Long-term residence in areas of high ozone: associations with respiratory health in a nationwide sample of nonsmoking young adults. Environ Health Perspect 1999; 107: 675-679.

36 Kan H, Heiss G, Rose KM, et al. Traffic exposure and lung function in adults: the Atherosclerosis Risk in Communities study. Thorax 2007; 62: 873-879.

37 Jedrychowski W, Krzyzanowski M. Ventilatory lung function and chronic chest symptoms among the inhabitants of urban areas with various levels of acid aerosols: prospective study in Cracow. Environ Health Perspect 1989; 79: $101-107$

38 Dubowsky SD, Suh H, Schwartz J, et al. Diabetes, obesity, and hypertension may enhance associations between air pollution and markers of systemic inflammation. Environ Health Perspect 2006; 114: 992-998.

39 Zeka A, Sullivan JR, Vokonas PS, et al. Inflammatory markers and particulate air pollution: characterizing the pathway to disease. Int J Epidemiol 2006; 35: 1347-1354

40 Cai Y, Schikowski T, Adam M, et al. Cross-sectional associations between air pollution and chronic bronchitis: an ESCAPE meta-analysis across five cohorts. Thorax 2014; 69: 1005-1014.

41 Department for Environment Food and Rural Affairs. Emissions of Air Pollutants in the UK, 1970 to 2017. https://assets.publishing.service.gov.uk/government/uploads/system/uploads/attachment_data/file/778483/ Emissions_of_air_pollutants_1990_2017.pdf 2019. 